\title{
Differentiation of heroin and cocaine using dual-energy CT_an experimental study
}

\author{
Jochen Grimm • Ramona Wudy • Edvard Ziegeler • \\ Stefan Wirth • Michael Uhl • Maximilian F. Reiser • \\ Michael Scherr
}

Received: 4 November 2013 / Accepted: 13 February 2014 / Published online: 28 February 2014

(C) Springer-Verlag Berlin Heidelberg 2014

\begin{abstract}
Objective To evaluate if heroin and cocaine can be distinguished using dual-energy $\mathrm{CT}$.

Materials and methods Twenty samples of heroin and cocaine at different concentrations and standardized compression (SC) were scanned in dual-energy mode on a newest generation Dual Energy 64-row MDCT scanner. CT number, spectral graphs, and dual-energy index (DEI) were evaluated. Results were prospectively tested on six original samples from a body packer. Wilcoxon's test was used for statistical evaluation. Results Values are given as median and range. Under SC, the CT number of cocaine samples ( -29.87 Hounsfield unit (HU) $[-125.85 ; 16.16 \mathrm{HU}])$ was higher than the CT number of heroin samples $(-184.37$ HU $[-199.81 ;-159.25 \mathrm{HU}]$; $p<0.01)$. Slope of spectral curves for cocaine was $-2.36 \mathrm{HU} / \mathrm{keV}[-7.15 ;-0.67 \mathrm{HU} / \mathrm{keV}]$, and for heroin, $1.75 \mathrm{HU} / \mathrm{keV}[1.28 ; 2.5 \mathrm{HU} / \mathrm{keV}](p<0.01)$. DEI was $0.0352[0.0081 ; 0.0528]$ for cocaine and significantly higher than for heroin samples $(-0.0127[-0.0097 ;-0.0159]$; $p<0.001$ ). While CT number was inconclusive, all six original
\end{abstract}

J. Grimm • R. Wudy • E. Ziegeler · S. Wirth $\cdot$ M. F. Reiser •

M. Scherr

Institute for Clinical Radiology, Ludwig-Maximilians-University

Hospital Munich, Nussbaumstraße 20, 80336 Munich, Germany

J. Grimm ( $₫)$

Department of Medical Radiology, University Hospital and

University of Lausanne, Rue du Bugnon 46, 1011 Lausanne,

Switzerland

e-mail: jochen.grimm@chuv.ch

J. Grimm

Center for Legal Medicine Lausanne and Geneva,

Rue du Bugnon 21, 1011 Lausanne, Switzerland

M. Uhl

Bavarian State Criminal Police Office, Maillingerstrasse 15, 80636 Munich, Germany packs were correctly classified after evaluation of the spectral curve and DEI. In contrast to the CT number, slope of the spectral curve and DEI were independent of concentration and compression.

Conclusion The slope of the spectral curve and the DEI from dual-energy CT data can be used to distinguish heroin and cocaine in vitro; these results are independent of compression and concentration in the measured range.

Keywords Body packing · Dual-energy CT · Dual-energy index $\cdot$ Material differentiation $\cdot$ Illicit drugs

\section{Introduction}

Body packers, pushers, and stuffers ingest a variable number of packs filled with illicit drugs by swallowing (classical body packers and body stuffers) or inserting them rectally or vaginally (body pushers), e.g., in order to smuggle them across borders $[1,2]$. In the western hemisphere, cocaine and heroin pose the majority of illicit drugs transported by body packers [3-5], whereas other drugs play a minor role.

The number of cases of intracorporeal drug smuggling in Europe and the USA has been rising continually, especially during recent years $[6,7]$. As a result, medical practitioners, particularly at emergency departments, are increasingly confronted with diagnostic and therapeutic challenges in the context of body packing [6-10]. On the diagnostic side, radiological imaging has played an important part. It can be crucial to detect and localize incorporated packs both in purely forensic as well as in mainly medical indications, when suspected body packers present with symptoms of bowel obstruction or drug intoxication [8,11-13]. Modern imaging techniques allow experienced radiologists to detect packs incorporated by suspected body packers with a high degree of certainty; computed tomography (CT) is becoming the first- 
line diagnostic modality with a sensitivity approaching $100 \%$ $[10,11,14-18]$.

Any single pack being smuggled regularly contains a lethal dose of the narcotic; so, pack rupture or leakage can cause lifethreatening symptoms of intoxication, the so-called body packer syndrome $[4,6,7,19,20]$. Today, no reliable means exist to distinguish leakage of a transported pack from consumption [21]. This decreases diagnostic confidence in emergency situations, as a body packer carrying cocaine may show signs of prior heroin abuse and vice versa. Current standard therapy for both heroin and cocaine body packers showing symptoms of intoxication is emergency laparotomy to immediately remove all packs, irrespective of the type of drug transported $[6,8,22]$. Complications of emergency laparotomy in body packers are reported to be higher than in laparotomies for other reasons, a fact that may be attributed to the frequent necessity of multiple intestinal incisions if large numbers of packs are carried [8, 23]. Heroin intoxication, however, can in some cases be treated conservatively by administration of the antidote naloxone under intensive care supervision $[12,20]$. It may also be helpful to know which substance an asymptomatic body packer is carrying to determine which effects of a potential intoxication need to be expected and the precautions that need to be taken.

As the body packer may be unable or unwilling to reveal the content of the carried packs, a method to objectively determine pack contents without patient cooperation would be helpful.

A few attempts regarding objective differentiation of illicit drugs can be found in the literature. Wackerle et al. were the first to publish radiation density measurements of illicit drugs in 1986 [9], suggesting that heroin and cocaine might be distinguished according to their Hounsfield units (HU) in CT. This approach appears questionable because radiation density should vary with the concentration, chemical structure and composition of the substance, and the method of pack manufacture [11, 24]. Especially the level of compression as a physical property of the examined material should heavily influence measured CT numbers [25]. Consequently, CT numbers reported for heroin and cocaine in the literature vary significantly [9, 14, 26-28]. Technical advances and the introduction of dual-energy CT scanners have made it possible to distinguish different materials. This technology has already been used to differentiate between various materials like different renal calculi [29-33] and is beginning to be applied in forensic imaging [34]. The use of dual-energy CT to distinguish heroin and cocaine in vitro has been reported in one experimental study by Leschka et al. [28] on hand-wrapped drug packets. This study, however, suffers from some major limitations impairing its comparability. Most importantly, it used an incorrect formula to calculate the dual-energy index (DEI) so that the dual-energy CT part of the study cannot be correctly interpreted. Furthermore, regarding attenuation measurements, the compression of the drug packages was neither known nor uniform between different packs so that it cannot be determined, if differences measured are to be attributed to changes in material composition or differing degrees of compression.

The purpose of our study was to eliminate these limitations and examine whether material differentiation using dualenergy CT (DECT) is robust regarding different degrees of concentration and compression and if it can be used to distinguish between the drugs most frequently carried by body packers in the western hemisphere: heroin and cocaine.

\section{Materials and methods}

\section{Experimental samples}

All samples were provided and all experiments were monitored by state authorities. In our experiments, we used six samples of heroin and eight samples of cocaine representing the vast majority of drugs smuggled by body packers. All of the 14 samples originated from different actual body packers and were analyzed by state authorities to contain different concentrations of between 20 and $38 \%$ heroin and between 21 and $78 \%$ cocaine hydrochloride, respectively.

\section{Experimental setup}

To exclude the influence of different mechanical manufacturing processes on imaging properties of body packs, we developed an experimental setup to apply a standardized amount of pressure on the samples. Each of the 14 samples was filled into a polycarbonate high-pressure syringe (CCSB911, Merit Medical, South Jordan, UT, USA) closed at the front and then compressed with a force $(F)$ of 1,000 N (see Fig. 1 for further details of the experimental setup). The compressing force applied was measured using an electronic precision dynamometer (PCE-FG 1k, PCE Deutschland GmbH, Meschede, Germany). Internal diameter $(D)$ of the syringe as provided by the manufacturer was $1.94 \mathrm{~cm}$; the internal cross-sectional area $(A)$ was circular and calculated to be $2.96 \mathrm{~cm}^{2}$ using the formula $A=1 /$ $4 \times \pi \times D^{2}$. The resulting pressure $(P)$ applied to the sample was $3,383 \mathrm{kPa}$ or $33.83 \mathrm{bar}$, calculated using the formula $P=F / A$.

\section{Original packs}

In February 2011, a 19-year-old male, who had swallowed 73 packs filled with illicit drugs, was under medical treatment at our institution. Six of these packs were provided to us by state authorities and scanned in their original state (Fig. 2). The analysis conducted by state authorities revealed that all six samples contained $77 \%$ cocaine hydrochloride, diluted with levamisole, and wrapped in aluminum foil and paraffin. All readers were blinded with regard to pack contents throughout the radiological part of the experiments. 

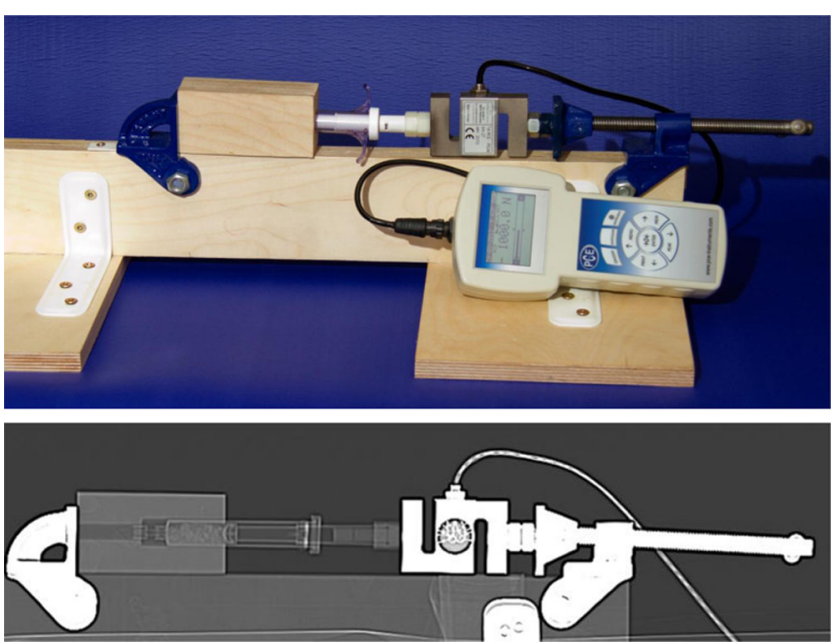

Fig. 1 Experimental setup for standardized compression. This figure shows a photograph of the experimental setup and a corresponding CT scan. The high-pressure syringe was filled with the drug sample and placed in the mainly wooden compression apparatus with an electronic pressure measuring device located between the syringe and the compression apparatus. To minimize artifacts, no metal parts were in the optical path during CT scans

\section{Original pack samples}

The six original packs were then opened for investigation by the Bavarian State Criminal Police Office and returned to us to repeat the measurements under the same standardized compression conditions used for the other samples in the first part of the experiment.

\section{CT scan parameters}

CT scans were obtained using a 64-row MDCT Scanner (CT750HD Discovery, GE Healthcare, Waukesha, Milwaukee). Scan parameters were as follows: tube voltage $80 / 140 \mathrm{kVp}$ (dual-energy mode), tube current $600 \mathrm{~mA}$, rotation time $1.0 \mathrm{~s}$,

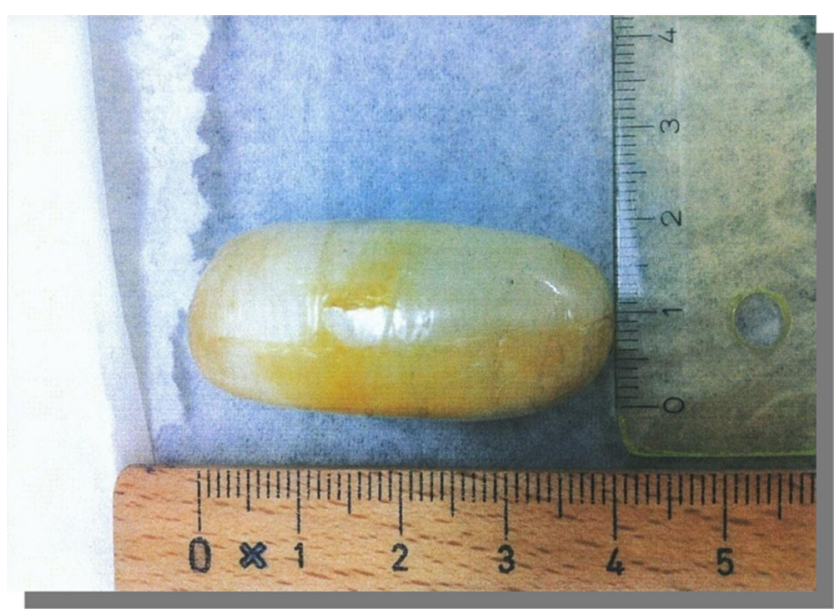

Fig. 2 Original body pack. This figure shows an original body pack from the body packer case containing $77 \%$ cocaine hydrochloride diluted with levamisole slice collimation $0.625 \mathrm{~mm}$, and pitch $0.984: 1$. Images were reconstructed in a soft tissue kernel to a slice thickness of $1.25 \mathrm{~mm}$.

Image evaluation

Image evaluation was done by two radiologists with 4 (JMG) and 11 (MS) years of experience in CT evaluation and one medical student (RMW) in consensus. A circular region of interest (ROI) of approximately $100 \mathrm{~mm}^{2}$ was placed in the lumen of each syringe or original pack on axial reconstructions; inclusion of the syringe or pack wall was carefully avoided.

The scanner's software for dual-energy evaluation (Gemstone Spectral ImagingTM, GE Healthcare, Waukesha, Milwaukee) was used to generate a spectral graph from each of the ten ROIs for each sample. This graph plots CT number in $\mathrm{HU}$ ( $y$-axis) as a function of photon energy ranging from 40 to $140 \mathrm{keV}$ (x-axis). To numerically evaluate characteristics of the spectral curves, the average slope was calculated as $\Delta(\mathrm{HU}) / \Delta(\mathrm{keV})$, i.e., $\Delta(y) / \Delta(x)$. Average slopes were evaluated between 40 and $80 \mathrm{keV}$ because slopes tend to be greater at lower $\mathrm{keV}$ levels so that the greatest differences were expected at low keV levels. For comparison with CT scanners of different manufacturers, the dual-energy index (DEI) was also calculated according to the formula ( $\mathrm{HU}$ at $80 \mathrm{kVp}-\mathrm{HU}$ at $140 \mathrm{kVp}) /(\mathrm{HU}$ at $80 \mathrm{kVp}+\mathrm{HU}$ at $140 \mathrm{kVp}+2,000)$ [35].

With the scanner's software, it is also possible to compute monochromatic images from the dual-energy data set for any desired keV level between 40 and 140. The mean CT number of each ROI was measured in a computed monochromatic 65$\mathrm{keV}$ image, which we found to be the closest match of the clinical standard for abdominal CT at $120 \mathrm{kVp}$ tube voltage. The DEI was calculated post hoc from monochromatic images at $45 \mathrm{keV}$ (most closely representing $80 \mathrm{kVp}$ ) and $75 \mathrm{keV}$ (most closely representing $140 \mathrm{kVp}$ ).

Statistical analysis

Statistical analysis was performed using Wilcoxon's test for independent samples (SPSS 20, IBM Corp., Armonk, NY, USA). A $p$ value $<0.01$ was considered statistically significant.

\section{Results}

As normal distribution cannot be assumed, values for CT number and average slope are given as median and range. Table 1 shows an overview.

Experimental samples

Under standard compression conditions, the $\mathrm{CT}$ number of the cocaine samples $(-29.87 \mathrm{HU}[-125.85 ; 16.16 \mathrm{HU}])$ was 
Table 1 CT number, average slope of the spectral curve, and dual-energy index

\begin{tabular}{lccc}
\hline Type of drug & CT number at $65 \mathrm{keV}[\mathrm{HU}]$ & Average slope $[\mathrm{HU} / \mathrm{keV}]$ & Dual-energy index \\
\hline Heroin SC & $-184.37[-159.25 ;-199.81]$ & $1.75[1.28 ; 2.5]$ & $-0.013[-0.001 ;-0.016] ;$ \\
Cocaine SC & $-29.87[-125.85 ; 16.16]$ & $-2.36[-7.15 ;-0.67]$ & $0.035[0.008 ; 0.053]$ \\
Body packs original state & $65.71[46.57 ; 80.80]$ & $-5.27[-5.83 ;-4.75]$ & $0.044[0.042 ; 0.053]$ \\
Body packs SC & $-64.14[-85.29 ;-49.14]$ & $-5.59[-5.77 ;-2.5]$ & $0.035[0.034 ; 0.036]$ \\
\hline
\end{tabular}

All values are given as median and range

$H U$ Hounsfield units $S C$ standardized compression

higher than the $\mathrm{CT}$ number of the heroin samples $(-184.37 \mathrm{HU}[-199.81 ;-159.25 \mathrm{HU}] ; p<0.01)$.

The spectral graphs of all cocaine samples showed a falling curve with a negative average slope of $-2.36 \mathrm{HU} / \mathrm{keV}[-7.15$; $-0.67 \mathrm{HU} / \mathrm{keV}]$. In contrast, all graphs for heroin samples showed a rising curve with a positive average slope of $1.75 \mathrm{HU} / \mathrm{keV}[1.28 ; 2.5 \mathrm{HU} / \mathrm{keV}]$, significantly differing from the slopes of the cocaine samples $(p<0.001)$. Figure 3 displays spectral graphs. The DEI for heroin samples was -0.0127 $[-0.0097 ;-0.0159]$ and significantly lower than for cocaine samples $(0.0352$ [0.0081;0.0528]; $p<0.001)$.

With these results, the hypothesis was proposed that average slopes of spectral curves of heroin samples are positive, while they are negative for cocaine samples. The opposite should hold true for the DEI.

We had the opportunity to test this hypothesis on six samples from a body packer, who presented at our hospital shortly after completion of the described experiments.

\section{Original packs}

Median CT number of the six original packs was $65.71 \mathrm{HU}$ [46.57; 80.8 HU]. In their original state, the CT number of the packs differed significantly from both cocaine and heroin samples measured in the first part of the experiment $(p<0.01$, respectively).
Spectral graphs for all six samples in their original state showed a falling curve with a median slope of $-5.27 \mathrm{HU} /$ $\mathrm{keV}[-5.83 ;-4.75 \mathrm{HU} / \mathrm{keV}]$. This value differed significantly from slopes of the heroin samples $(p<0.01)$, but not from slopes of the cocaine samples $(p=0.14)$ from the first part of the experiment. Accordingly, the median DEI was found to be 0.044 [0.042; 0.053], higher than for heroin $(p<0.01)$ but not significantly different from cocaine samples $(p=0.28)$.

Original pack samples

After standardized compression at 33.83 bar as described above, the CT number of the six samples was $-64.14 \mathrm{HU}$ $[-85.29 ;-49.14 \mathrm{HU}]$, significantly different from measurements in their original state $(p<0.01)$. At standardized compression, no significant difference of the CT number was observed when compared to the cocaine samples $(p=0.14)$. However, when compared to the heroin samples from the first part of the experiment, the difference in CT number was statistically significant $(p<0.01)$.

Spectral graphs for all six samples showed a falling curve with an average slope of $-5.59 \mathrm{HU} / \mathrm{keV}[-5.77 ;-2.50 \mathrm{HU} /$ $\mathrm{keV}]$ and a DEI of 0.035 [0.034; 0.036]. Again, when compared to the cocaine samples from the first part of the experiment, no significant difference was observed for the average

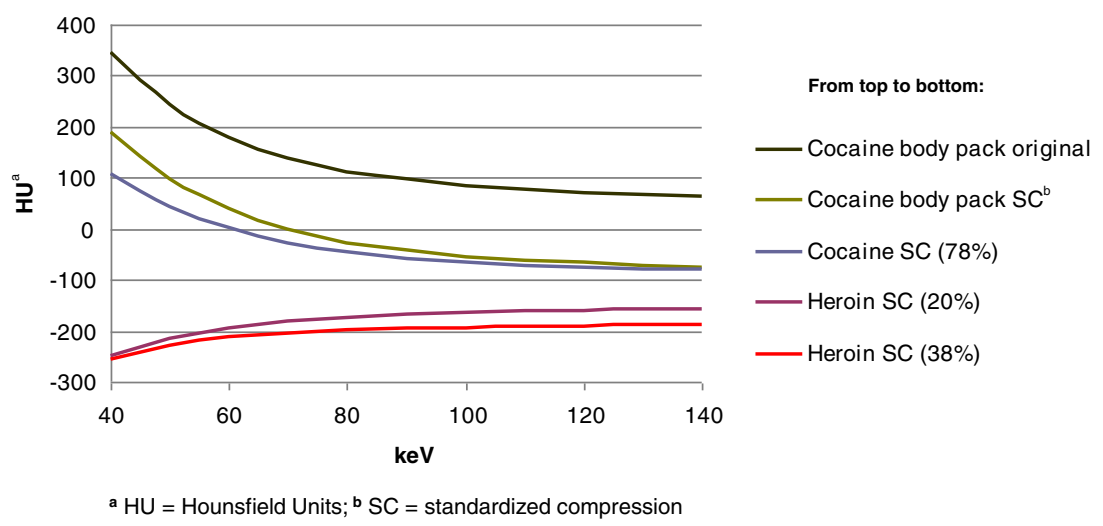

Fig. 3 Spectral curves of heroin and cocaine. This figure shows representative spectral graphs of two heroin and one cocaine samples from the first part of the experiment as well as graphs of an original pack from the body packer case both in its original state and after standardized compression. Other curves were similar and are not displayed for better readability. Note the higher density of the curve for the original pack which results in an upward displacement of the curve on the plot without changing its slope 
slope and DEI ( $p=0.24$ and 0.75 , respectively); while in comparison to the heroin samples, the difference of the average slope and DEI was statistically significant (both $p<0.01$ ). The distribution of average slopes and DEI of all samples is displayed in Fig. 4.

a

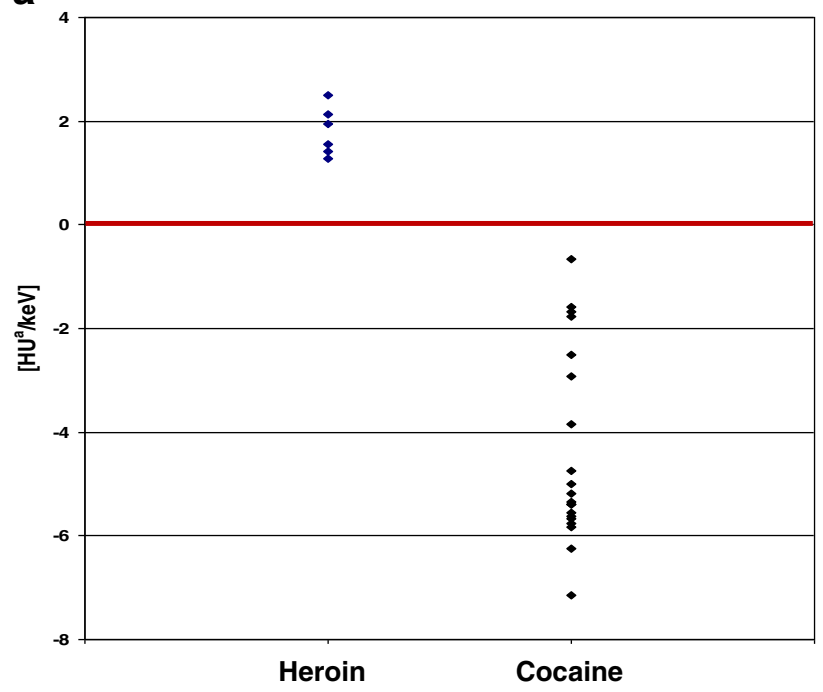

a $\mathrm{HU}=$ Hounsfield Units

b

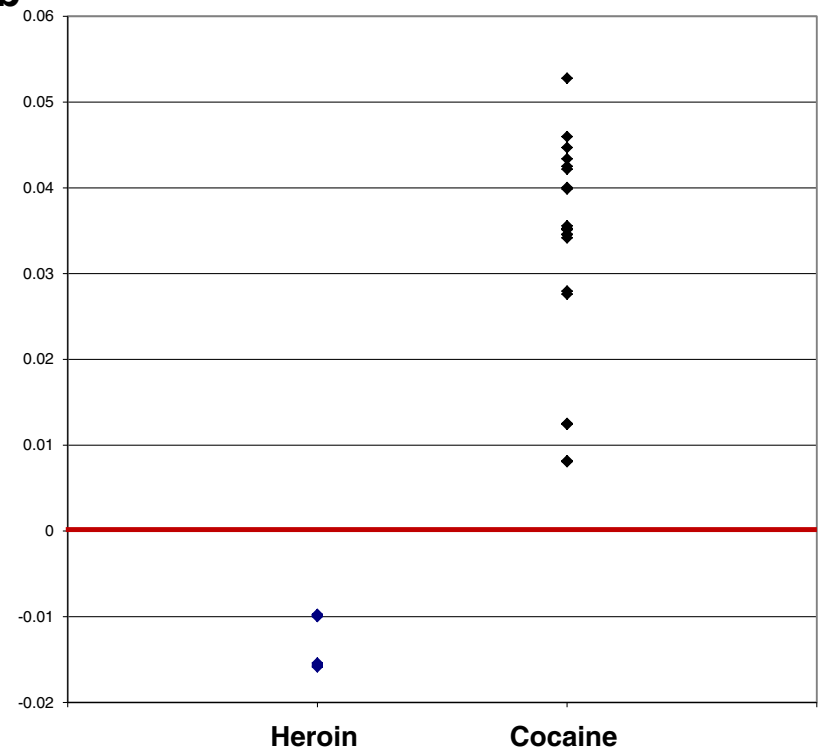

Fig. 4 a Average slopes of spectral curves for heroin and cocaine. This figure shows the average slope of spectral curves of heroin and cocaine from all samples used in our experiments in comparison. Note the grouping of values for cocaine below and for heroin above zero representing rising spectral curves for heroin and dropping curves for cocaine. b Dual-energy index for heroin and cocaine. This figure shows the dual-energy index of heroin and cocaine from all samples used in our experiments in comparison. Note the grouping of values comparable to the average slope, but for the dual-energy index of cocaine above and for heroin below zero
According to our proposed hypothesis, we concluded that the packs should contain cocaine rather than heroin. This conclusion was confirmed by the chemical analyses of the drug samples.

\section{Discussion}

Differentiation of drugs using their CT number

Existing studies report $\mathrm{CT}$ numbers between 40 and $-520 \mathrm{HU}$ for heroin and between 247 and -219 HU for cocaine [9, 14, 26-28]. CT numbers observed for the original packs and under standardized compression conditions were in the range of values reported for both substances, though this range is extremely wide (Fig. 5). Similar to previous reports [9, 11, 28], cocaine samples showed higher CT numbers than heroin samples in our experiments.

\section{Influence of compression}

The cocaine body packs from the described case in their original form yielded a CT number significantly (on average around $130 \mathrm{HU}$ ) higher than the respective samples under standardized compression. Since the chemical properties of the samples from our case remained the same throughout our experiments, this difference in CT number can only be attributed to the degree of compression, suggesting a manufacturing process with a compression well beyond 33.38 bar for the original packs. This result is not surprising, as a higher physical density, i.e., mass per volume, for the same chemical substance can be expected to result in a higher CT number [25]. Thus, even for the same substance, different manufacturing processes using different degrees of compression lead to different physical densities of the fabricated packs which will consequently show different $\mathrm{CT}$ numbers.

\section{Influence of concentration}

In our study, $\mathrm{CT}$ numbers under standardized compression conditions ranged from -125.85 to $16.16 \mathrm{HU}$ for cocaine and from -199.81 to $-159.25 \mathrm{HU}$ for heroin samples, encompassing a range of roughly $140 \mathrm{HU}$ for cocaine and $40 \mathrm{HU}$ for heroin. Since the influence of different mechanical manufacturing processes was excluded by applying a standardized amount of pressure on all samples, this difference in CT number can only be attributed to varying chemical properties like concentration of a substance and the diluents used.

This study, to our knowledge, presents the first report of using a standardized compression to exclude the influence of the manufacturing process of illicit drug packages on CT number measurements. When this is not done, as in most 


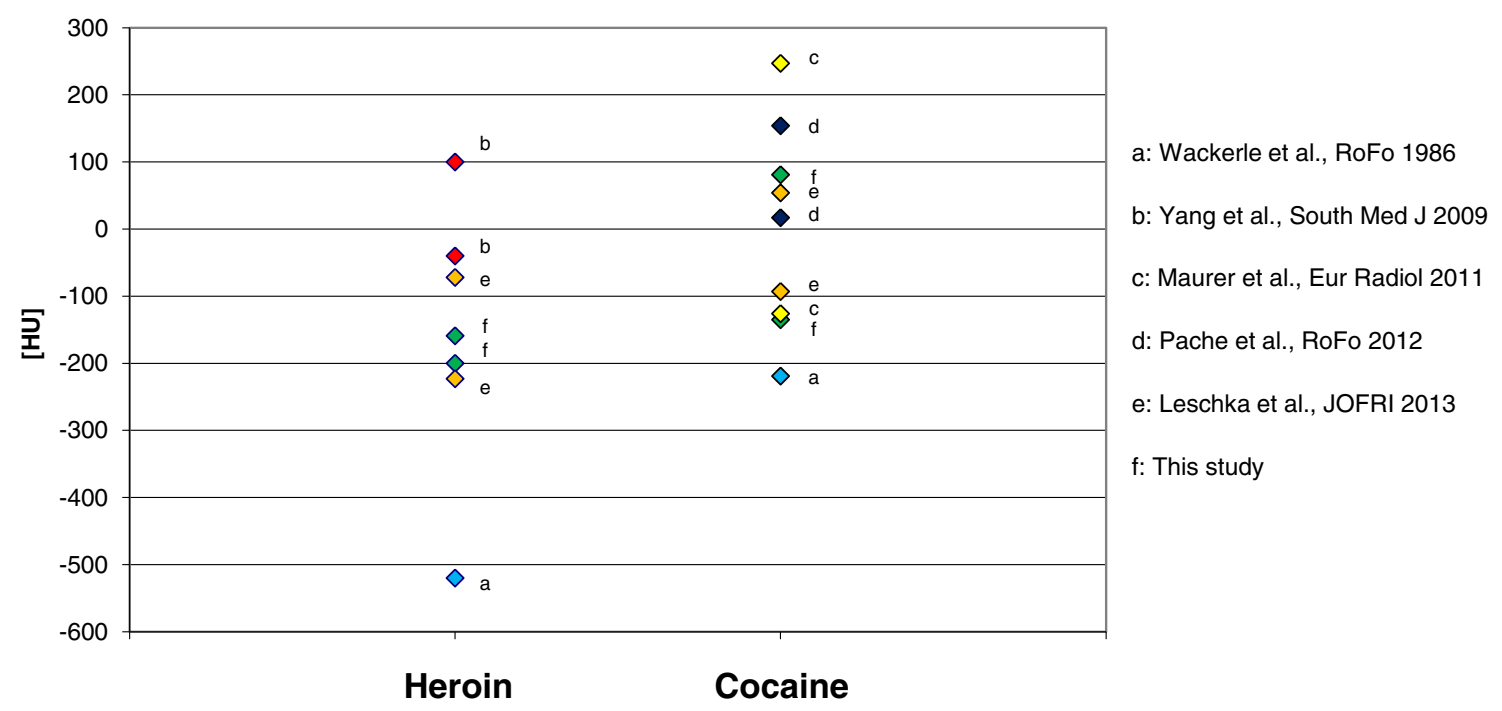

${ }^{*} \mathrm{HU}=$ Hounsfield Units

Fig. $5 \mathrm{HU}$ values reported for heroin and cocaine. This figure shows the $\mathrm{HU}$ values for heroin and cocaine reported in the literature until today, irrespective of concentration and degree of compression. If more than two values were reported, the highest and the lowest reported CT numbers are

existing studies, it is impossible to distinguish the influence of compression from the influence of chemical composition.

Thus, our study supports the thesis that the CT number of drug samples is greatly dependent on the manufacturing process $[11,26,28]$ so that a reliable distinction of heroin and cocaine using the $\mathrm{CT}$ number is not possible when concentration and compression are unknown. When the influence of the respective other variable was excluded, changes in compression and chemical properties of heroin and cocaine samples resulted in major changes of their $\mathrm{CT}$ number in our experiments. A differentiation of narcotics using their CT number may be possible only if the concentration and degree of compression of the different samples compared is identical or at least known to the observer. Since this information will regularly be impossible to obtain under clinical conditions, the CT number is impractical to distinguish between heroin and cocaine of unknown manufacturing process.

\section{Differentiation of illicit drugs using dual-energy CT}

The differentiation of illegal drugs using the average slope of their spectral curve or the correct DEI has to our knowledge not been reported yet. As mentioned before, Leschka et al. [28] unfortunately used an incorrect formula for calculation of the DEI, so that their results cannot be compared to ours or the existing literature. Our experiments suggest that a differentiation of heroin and cocaine is possible by evaluating the spectral curve from a dual-energy CT as well as by using the DEI of the substance examined. In our experiments, we found a negative average slope and positive DEI for cocaine, and a positive average slope and negative DEI for heroin. In contrast displayed in the diagram. If multiple tube voltages were used, only the values for $120 \mathrm{kVp}$ are given. Note the large overlap between values for heroin and cocaine demonstrating the impracticability of a distinction between both substances using their CT number

to the CT number, both average slope and DEI were independent of concentration and compression of the drug samples in the range examined.

Based on these findings, the hypothesis can be formulated that cocaine should show a higher average slope and lower DEI than heroin with a cutoff value close to zero for both parameters.

The DEI delivered statistically comparable results to the average slope of the spectral curve and seems to be equally well suited to differentiate heroin and cocaine.

\section{Limitations}

One limitation of our study is the relatively small number of samples. This is owed to the sensitive nature of the examined substances and well in the range of existing publications. We did not evaluate the influence of different diluents, as the number of substances used to dilute drugs was too large to be evaluated in our relatively small sample. It can be expected that the influence of diluents on imaging characteristics of drugs increases with decreasing drug concentration. However, since body packers usually carry drugs at relatively high concentrations to increase market value of the load, this influence is likely to be lower than in concentrations adapted for consumption. Furthermore, the independency of the DEI and slope of the spectral curve from concentration and compression of the drug samples in the range examined shows that our proposed method of differentiation is robust.

Our results are based on in vitro examinations. Therefore, the method needs to be further validated in animal models 
and/or in vivo before being considered for routine clinical application.

\section{Conclusion}

Results of our study confirm that the CT number is not a suitable indicator for the type of drug being transported by a body packer. It varies greatly with different concentration and compression of a substance, parameters which are unlikely to be obtainable under clinical conditions.

A distinction of heroin and cocaine seems possible using the average slope of the spectral curve and the DEI from dualenergy spectral imaging CT data. In vitro, these parameters deliver significant differences between both substances, independent of concentration and compression of the samples. If confirmed, these results might alter clinical handling of symptomatic body packers.

Conflict of interest The authors declare that they have no conflict of interest.

\section{References}

1. United Nations Office on Drugs and Crime (2010) World drug report 2010 (United Nations Publication). United Nations Office on Drugs and Crime (UNODOC), Vienna. (2010). Available via http://www. unodc.org/documents/wdr/WDR_2010/World_Drug_Report_2010_ lo-res.pdf

2. Bulstrode N, Banks F, Shrotria S (2002) The outcome of drug smuggling by 'body packers'-the British experience. Ann R Coll Surg Engl 84(1):35-38

3. Stewart A, Heaton ND, Hogbin B (1990) Body packing - a case report and review of the literature. Postgrad Med J 66(778):659-661

4. Traub SJ, Hoffman RS, Nelson LS (2003) Body packing - the internal concealment of illicit drugs. N Engl J Med 349(26):2519-2526. doi:10.1056/NEJMra022719

5. Claffey M (2002) Stampede of drug mules at Kennedy: after 9/11 lull, heroin and ecstasy busts soar. New York Daily News, May 5, 2002, p 1

6. de Bakker JK, Nanayakkara PW, Geeraedts LM Jr, de Lange ES, Mackintosh MO, Bonjer HJ (2012) Body packers: a plea for conservative treatment. Langenbeck's Arch Surg 397(1):125-130. doi:10. 1007/s00423-011-0846-Z

7. Silverberg D, Menes T, Kim U (2006) Surgery for "body packers"a 15-year experience. World J Surg 30(4):541-546. doi:10.1007/ s00268-005-0429-7

8. de Beer SA, Spiessens G, Mol W, Fa-Si-Oen PR (2008) Surgery for body packing in the Caribbean: a retrospective study of 70 patients. World J Surg 32(2):281-285. doi:10.1007/s00268-007-9316-8, discussion 286-287

9. Wackerle B, Rupp N, von Clarmann M, Kahn T, Heller H, Feuerbach S (1986) Detection of narcotic-containing packages in "bodypackers" using imaging procedures. Studies in vitro and in vivo. Röfo 145(3):274-277. doi:10.1055/s-2008-1048932

10. Schmidt S, Hugli O, Rizzo E, Lepori D, Gudinchet F, Yersin B, Schnyder P, Meuwly JY (2008) Detection of ingested cocaine-filled packets - diagnostic value of unenhanced CT. Eur J Radiol 67(1): 133-138. doi:10.1016/j.ejrad.2007.07.017

11. Hergan K, Kofler K, Oser W (2004) Drug smuggling by body packing: what radiologists should know about it. Eur Radiol 14(4): 736-742. doi:10.1007/s00330-003-2091-5

12. Schaper A, Hofmann R, Ebbecke M, Desel H, Langer C (2003) Cocaine-body-packing. Infrequent indication for laparotomy. Chirurg 74(7):626-631. doi:10.1007/s00104-002-0603-5

13. Hutchins KD, Pierre-Louis PJ, Zaretski L, Williams AW, Lin RL, Natarajan GA (2000) Heroin body packing: three fatal cases of intestinal perforation. J Forensic Sci 45(1):42-47

14. Yang RM, Li L, Feng J, Lai SS, Lin BQ, Yu T, Ye XH, Xu YK (2009) Heroin body packing: clearly discerning drug packets using CT. South Med J 102(5):470-475. doi:10.1097/SMJ.0b013e31819ecacc

15. Ziegeler EGJ, Wirth S, Uhl M, Reiser MF, Scherr M (2012) Computed tomography scout views vs. conventional radiography in body-packers - delineation of body-packs and radiation dose in a porcine model. Eur J Radiol. doi:10.1016/j.ejrad.2012.06.030

16. Flach PM, Ross SG, Ampanozi G, Ebert L, Germerott T, Hatch GM, Thali MJ, Patak MA (2012) "Drug mules" as a radiological challenge: sensitivity and specificity in identifying internal cocaine in body packers, body pushers and body stuffers by computed tomography, plain radiography and Lodox. Eur J Radiol 81(10):2518-2526. doi:10.1016/j.ejrad.2011.11.025

17. Poletti PA, Canel L, Becker CD, Wolff H, Elger B, Lock E, Sarasin F, Bonfanti MS, Dupuis-Lozeron E, Perneger T, Platon A (2012) Screening of illegal intracorporeal containers ("body packing"): is abdominal radiography sufficiently accurate? A comparative study with low-dose CT. Radiology 265(3):772-779. doi:10.1148/radiol. 12112767

18. Brogdon BG, Vogel H, Algra PR (2010) Smuggling/border control. In: Brogdon's forensic radiology, 2nd edn. CRC, pp 297-310. doi:10. 1201/b10323-26

19. Wetli CV, Mittlemann RE (1981) The "body packer syndrome"toxicity following ingestion of illicit drugs packaged for transportation. J Forensic Sci 26(3):492-500

20. Booker RJ, Smith JE, Rodger MP (2009) Packers, pushers and stuffers - managing patients with concealed drugs in UK emergency departments: a clinical and medicolegal review. Emerg Med J 26(5): 316-320. doi:10.1136/emj.2008.057695

21. Mandava N, Chang RS, Wang JH, Bertocchi M, Yrad J, Allamaneni S, Aboian E, Lall MH, Mariano R, Richards N (2011) Establishment of a definitive protocol for the diagnosis and management of body packers (drug mules). Emerg Med J 28(2):98-101. doi:10.1136/emj. 2008.059717

22. Goertemoeller S, Behrman A (2006) The risky business of body packers and body stuffers. J Emerg Nurs 32(6):541-544. doi:10. 1016/j.jen.2006.07.014

23. East JM (2005) Surgical complications of cocaine body-packing: a survey of Jamaican hospitals. West Indian Med J 54(1):38-41

24. Raben AM, Phoa SS, Busch OR, Schultz MJ (2005) Case report of a smuggler's dinner: carrots and asparagus, or bolitas? Med Sci Monit 11(12):CS79-CS81

25. Novelline R (ed) (1997) Squire's fundamentals of radiology, 5th edn. Harvard University Press, Boston

26. Maurer MH, Niehues SM, Schnapauff D, Grieser C, Rothe JH, Waldmuller D, Chopra SS, Hamm B, Denecke T (2011) Low-dose computed tomography to detect body-packing in an animal model. Eur J Radiol 78(2):302-306. doi:10.1016/j.ejrad.2010.09.004

27. Pache G, Einhaus D, Bulla S, Baumann T, Langer M, Blanke P (2012) Low-dose computed tomography for the detection of cocaine body packs: clinical evaluation and legal issues. Röfo 184(2):122129. doi:10.1055/s-0031-1281781

28. Leschka S, Fornaro J, Laberke P, Blum S, Alkadhi H, Niederer I, Meile C, Hibbeln D, Hausmann R, Wildermuth S, Eisenhart D (2013) Differentiation of cocaine from heroine body packs by computed 
tomography: impact of different tube voltages and the dual-energy index. J Forensic Radiol Imaging 1(2):46-50. doi:10.1016/j.jofri. 2013.03.041

29. Coursey CA, Nelson RC, Boll DT, Paulson EK, Ho LM, Neville AM, Marin D, Gupta RT, Schindera ST (2010) Dual-energy multidetector CT: how does it work, what can it tell us, and when can we use it in abdominopelvic imaging? Radiographics 30(4):1037-1055. doi:10. 1148/rg.304095175

30. Hartman R, Kawashima A, Takahashi N, Silva A, Vrtiska T, Leng S, Fletcher J, McCollough C (2012) Applications of dual-energy CT in urologic imaging: an update. Radiol Clin N Am 50(2):191-205. doi: 10.1016/j.rcl.2012.02.007, v

31. Johnson TR, Krauss B, Sedlmair M, Grasruck M, Bruder H, Morhard D, Fink C, Weckbach S, Lenhard M, Schmidt B, Flohr T, Reiser MF, Becker CR (2007) Material differentiation by dual energy CT: initial experience. Eur Radiol 17(6):1510-1517. doi:10.1007/s00330-006$0517-6$
32. Manglaviti G, Tresoldi S, Guerrer CS, Di Leo G, Montanari E, Sardanelli F, Cornalba G (2011) In vivo evaluation of the chemical composition of urinary stones using dual-energy CT. AJR Am J Roentgenol 197(1):W76-W83. doi:10.2214/AJR.10.5217

33. Mongan J, Rathnayake S, Fu Y, Wang R, Jones EF, Gao DW, Yeh BM (2012) In vivo differentiation of complementary contrast media at dual-energy CT. Radiology. doi:10.1148/radiol.12120692

34. Ruder TD, Thali Y, Bolliger SA, Somaini-Mathier S, Thali MJ, Hatch GM, Schindera ST (2013) Material differentiation in forensic radiology with single-source dual-energy computed tomography. Forensic Sci Med Pathol 9(2):163-169. doi:10.1007/s12024-012-9398-y

35. Krauss B (2005) The dual-energy index. Siemens Healthcare AG, Siemens Medical 2005

The study was in accordance with local and international legislation. 